\title{
Handover:
}

\section{The Fragile Lines of Communication}

Andrew Smaggus MD, Adina S. Weinerman MD

\begin{abstract}
About the Authors
Andrew Smaggus is a staff physician in the Division of General Internal Medicine at Western University in London, Ontario. Adina S. Weinerman is a staff physician in the Division of General Internal Medicine, Sunnybrook Health Sciences Centre, Toronto, Ontario
\end{abstract}

\begin{abstract}
Summary
Handovers have been increasingly recognized as an important determinant of patient safety and quality of care. Changes in patterns of physician and resident work hours have increased the importance of safe handover. The current review summarizes previous literature on deficiencies in current handover practices, consequences of suboptimal handover, and barriers to effective handover. This review concludes by summarizing results of studies that used education, standardization, technology, and bundled interventions to improve handover.
\end{abstract}

\section{Introduction}

Handover is the act of transferring both the responsibility for a patient's care, and the information necessary to provide care, from one healthcare professional (or team) to another. Handover has increasingly been recognized as an important patient safety issue, especially as recent changes in physician and resident work hours have increased the need for safe handover practices. ${ }^{1}$ A study of handover frequency at an academic US centre found that on a one-month internal medicine clinical teaching unit rotation, a typical intern was involved in 300 patient handovers. In addition, a patient admitted for 5 days had their information handed-over approximately 15 times. ${ }^{2}$ The failure of duty-hour restrictions to improve measures of patient safety may be due to an increase in handovers. ${ }^{3,4}$ When the greater demands for handover are combined with the growing complexity of internal medicine patients, the potential consequences of inadequate handover on patient safety increase substantially.

This article will aim to review the current state of handover between physicians in the inpatient medical setting, using a quality improvement perspective.

\section{What problems exist in current handover practices?}

Many early studies of handover were single-centre audits that identified content omissions in handover (summarized in Table 1) ${ }^{5,6,7,8}$ Surprisingly, some of the omitted content (e.g. current status, active medical problems) was vital information. Estimating the frequency of these omissions is difficult, as the goal of these studies was primarily to characterize the omitted information. However, the nature of this omitted information highlights the potential impact of handover on patient safety.

Unlike handover content, deficiencies of the handover process have not been studied as often. The most in-depth investigation involved retrospective interviews with residents who were asked to recall adverse events in which suboptimal handover occurred. ${ }^{8}$ Using this method, the most commonly identified deficiency in the process was the lack of face-toface communication during handover. Other identified process deficiencies that lead to communication breakdowns were illegible handwriting and double handovers, where the primary team handed over to a covering physician, who then handed over to another physician (as often occurs in 
night-float systems). One study demonstrated that $41 \%$ of handovers at one institution (which utilizes a night float system) did not involve a physician from the patient's primary team. ${ }^{7}$

Table 1. Classification and examples of omitted handover content. Anticipatory guidance refers to instructions provided to covering physicians to be carried out if a potentially foreseeable event occurs.

\begin{tabular}{|c|c|}
\hline Omitted Content & Example(s) \\
\hline $\begin{array}{l}\text { Active medical problems/ } \\
\text { current clinical status }\end{array}$ & $\begin{array}{l}\text { - Failure to inform covering MD of active } \\
\text { bronchospasm requiring bronchodilator } \\
\text { therapy that day. Patient required } \\
\text { transfer to higher level of care. } \\
\text { - Failure to inform covering MD of } \\
\text { elevated BPs in a patient who had } \\
\text { required multiple doses of IV anti- } \\
\text { hypertensives. }^{8}\end{array}$ \\
\hline Recent significant events & $\begin{array}{l}\text { - Episode of hypoglycemia in a patient } \\
\text { with diabetes (treated with insulin) not } \\
\text { handed over. }^{5}\end{array}$ \\
\hline $\begin{array}{l}\text { Pending events and } \\
\text { investigations }\end{array}$ & $\begin{array}{l}\text { - Failure to notify covering MD of multiple } \\
\text { pending consults from subspecialties. }{ }^{8}\end{array}$ \\
\hline Rationale for desired action & $\begin{array}{l}\text { - Covering MD not informed of rationale } \\
\text { for MRI (to define anatomy prior to OR } \\
\text { planned for the next morning). MRI } \\
\text { was not performed. }^{5} \\
\text { - Failure to include rationale for not } \\
\text { initiating antibiotics leading to } \\
\text { uncertainty. }\end{array}$ \\
\hline Anticipatory guidance & $\begin{array}{l}\text { - Attempts at guidance either absent, or } \\
\text { vague ("If you are called regarding high } \\
\text { blood sugars, can you start insulin?"). }{ }^{7}\end{array}$ \\
\hline
\end{tabular}

\section{What are the consequences of deficiencies in handovers?}

The potential for handover to affect the quality of patient care has been suspected for many years. A study from the 1990s suggested a link between discontinuity of physician coverage and adverse events. ${ }^{9}$ Years later, in a review of almost 5000 sentinel events, the Joint Commission concluded that communication failures (including handover) contributed to $60-80 \%$ of preventable patient safety incidents. ${ }^{10,11}$
While these studies implicated handover as a cause of harm to patient, direct evidence of handover leading to adverse events has been difficult to demonstrate. One study that did investigate patient harms identified adverse events that could be attributed to handover at a rate of 7.5 per 100 patient days. ${ }^{5}$

Evidence of harm from handover issues has also been inferred from malpractice claims. A study of missed or delayed diagnoses identified approximately $20 \%$ and $24 \%$ of claims involved inadequate handover in ambulatory care and the emergency department, respectively. ${ }^{12,13}$

The perception of postgraduate trainees is that handover problems contribute to adverse events. When surveyed, residents in internal medicine and surgical specialties believed that $9.4 \%$ of patients they had cared for had suffered harm due to a handover problem and $12.3 \%$ of those harms had major consequences. ${ }^{6}$

\section{What are the barriers to effective handover?}

The transfer of information is a recognized source of error in multiple professions. ${ }^{14}$ From a systems perspective, the lack of standardized processes is a major barrier to efficient handover. In many institutions, handover is carried out in a haphazard manner according to the availability of physicians. ${ }^{15}$ The lack of a consistent, dedicated space for handover may contribute to the high frequency of interruptions that affect handover. ${ }^{16}$ The cognitive psychology literature suggests that interruptions can have deleterious effects on tasks, like handover, that have high demands on working memory. ${ }^{17}$

Time pressures may contribute to the failure of the primary team to provide detailed instructions and for the covering physicians to ask questions and seek clarification. It has been estimated that each patient is discussed for an average of 35 seconds during handover, leaving little time for questions or clarification. ${ }^{7}$

Another systemic issue affecting handover quality is a lack of specific training regarding handover during medical school and residency. A survey of internal medicine training programs in 2006 indicated that $60 \%$ of programs did not provide any instruction in handover. ${ }^{18}$

In addition to these systems issues, there are cognitive aspects to handover that affect the individuals involved. In many academic centres, handover is often carried out between a senior resident and a junior resident. Though other industries have a greater appreciation of how hierarchies affect the transfer of information these may be just as pertinent in medicine. ${ }^{19}$ However, the one study that reported on this 
phenomenon found little evidence that it affected handover between interns and senior residents. ${ }^{7}$

Another cognitive factor that may affect handover is the 'egocentric bias' demonstrated in a study in which residents were asked to estimate the effectiveness of their handover. Residents who provided handover expected on-call residents to recall important pieces of information more effectively than the on-call residents were able to when tested (2.6 vs. $1.6, p<0.01) .^{20}$

While this overestimation of the effectiveness of handover may reflect an egocentric bias on the individual providing handover, the high complexity of the information communicated may also affect the ability of on-call physicians to retain salient points. Previous research has suggested that attention and engagement vary as the complexity of a task increases, ${ }^{21,22}$ which may contribute to the lack of questioning observed during handover sessions. ${ }^{7}$

\section{What interventions to improve handover have been studied?}

Many institutions have pursued quality improvement initiatives that focus on handover. The formats of these attempts differ, but most include education, standardization, implementation of technology, or a combination of these (i.e. bundled interventions).

\section{Education}

In the context of quality improvement, education is used to address gaps in knowledge that contribute to deficient practices. However, as an intervention, education is generally regarded as having limited effectiveness. ${ }^{23,24}$ Educational interventions to improve handover quality were addressed in a systematic review that found improvements were generally limited to attitudes, knowledge, and skills and not to actual behavior change or performance. ${ }^{25}$

One educational intervention that appears promising is teamwork training. This has been used in other industries to improve communication between team members, and to overcome barriers created by authority gradients. ${ }^{19}$ While not studied on its own, teamwork training has begun to be introduced into bundled interventions to improve handover (see below).

\section{Standardization}

Standardization of processes, with integration of safe practices, is regarded as a more effective intervention to improve safety than education. ${ }^{23,24}$ Many centres have attempted to strengthen handover through standardization. ${ }^{26}$

Handover mnemonics are a standardization attempt to assist clinicians in remembering the important content of handover and to provide structure to the handover process. A large number of handover mnemonics (e.g. SIGNOUT, HANDOFFS, ANTICipate) have been developed, intended for use in a variety of settings (e.g. inpatient setting, emergency department) ${ }^{27}$

Isolated studies of standardization attempts have documented increased comfort, confidence, and satisfaction in handover content amongst trainees. ${ }^{28,29}$ One study also demonstrated a perception amongst trainees that the standardized handover format led to increased updates to patients and family members. More definitive evidence (i.e. beyond the perceptions of physicians) has not been measured.

\section{Technology}

The use of technology has proven to be an effective method of improving handover. ${ }^{23,24}$ Multiple studies have demonstrated an association between the implementation of a computerized handover tool and an improvement in measures of handover quality. One study demonstrated a reduction in content omissions following implementation of a computerized sign-out tool, ${ }^{30}$ while another found that the reported accuracy of handover was higher after the implementation of an online signover. ${ }^{31}$

Adverse events (defined as events that prolonged hospital stay or resulted in patient disability), as reported by physicians, were found to be lower following the implementation of a computerized handover tool. ${ }^{32}$

\section{Bundled Interventions}

Early investigations demonstrated the potential of bundled interventions to improve measures of handover quality. ${ }^{33,34}$ The most impressive results from a handover intervention were recently reported from a study involving a bundled intervention for pediatric residents. This before and after study investigated the effect of a "handoff bundle" (teamwork training, use of the I-PASS mnemonic and a structured sign-over tool) on errors on 2 pediatric wards within a single centre. Medical errors occurred significantly less frequently in the 3 -month period after the implementation of the handover bundle compared to a 3-month period before its implementation (18.3 vs. 33.8 medical errors per 100 admissions, $\mathrm{p}<0.001)$. Fewer content omissions were noted after the bundle was implemented, and 
no differences in the time spent handing over were observed. ${ }^{35}$ Though the study had limitations, ${ }^{36}$ it demonstrated the possibility to reduce patient harm with improvements in handover.

\section{Conclusion}

The changing profile of physician work hours has increased the need for effective handover. As with other quality improvement initiatives, the greatest benefits have been demonstrated following implementation of bundled interventions. While these findings are promising, evidence linking improved handover to improved patient safety is still sparse, and many barriers to effective handover remain poorly addressed. As demands for high value care increase, handover is likely to remain a key target for quality improvement interventions.

\section{References}

1. National Steering Committee on Resident Duty Hours. 2013. Fatigue, Risk and Excellence: Towards a Pan-Canadian Consensus on Resident Duty Hours. Ottawa, Ontario: The Royal College of Physicians and Surgeons of Canada.

2. Vidyarthi AR, Arora V, Schnipper JL, Wall SD, Wachter RM. Managing discontinuity in academic medical centers: Strategies for a safe and effective resident sign-out. J Hosp Med 2006;1:257-266.

3. Moonesinghe SR, Lowery J, Shahi N, Millen A, Beard JD. Impact of reduction in working hours for doctors in training on postgraduate medical education and patients' outcomes: Systematic review. BMJ 2011;342:15801592.

4. Pattani R, Wu PE, Dhalla IA. Resident duty hours in Canada: Past, present and future. CMAJ 2014;186:761-765.

5. Horwitz LI, Moin T, Krumholz HM, Wang L, Bradley EH. Consequences of inadequate sign-out for patient care. Arch Intern Med 2008;168:1755-1760.

6. Kitch BT, Cooper JB, Zapol WM, et al. Handoffs causing patient harm: A survey of medical and surgical house staff. Jt Comm J Qual Patient Saf 2008;34:563-570.

7. Horwitz LI, Moin T, Krumholz HM, Wang L, Bradley EH. What are covering doctors told about their patients? Analysis of sign-out among internal medicine house staff. Qual Saf Health Care. 2009;18:248-255.

8. Arora V, Johnson J, Lovinger D, Humphrey HJ, Meltzer DO. Communication failures in patient sign-out and suggestions for improvement: A critical incident analysis. Qual Saf Health Care. 2005;14:401-407.

9. Petersen LA, Brennan TA, O’Neil AC, Cook EF, Lee TH. Does housestaff discontinuity of care increase the risk for preventable adverse events? Ann Intern Med 1994;121:866-872.

10. The Joint Commission. Joint Commission Center for Transforming Healthcare releases targeted solutions tool for hand-off communications. Available at: http://www.jointcommission.org/assets/1/6/TST_HOC_ Persp_08_12.pdf. Accessibility verified September 10, 2014.

11. The Joint Commission. Sentinel event data: root causes by event type 2004-2013. Available at: http://www.jointcommission.org/assets/1/18/Root Causes_by_Event_Type_2004-2Q2013.pdf Accessibility verified September $10,2014$.
12. Gandhi TK, Kachalia A, Thomas EJ, et al. Missed and delayed diagnoses in the ambulatory setting: A study of closed malpractice claims. Ann Intern Med 2006;145:488-496.

13. Kachalia A, Gandhi TK, Puopolo AL, et al. Missed and delayed diagnoses in the emergency department: A study of closed malpractice claims from 4 liability insurers. Ann Emerg Med 2007;49:196-205.

14. Patterson ES, Roth EM, Woods DD, Chow R, Gomes JO. Handoff strategies in settings with high consequences for failure: Lessons for health care operations. Int J Qual Health Care. 2004;16:125-132.

15. Horwitz LI, Krumholz HM, Green ML, Huot SJ. Transfers of patient care between house staff on internal medicine wards: A national survey. Arch Intern Med 2006;166:1173-1177.

16. Estryn-Behar MR, Milanini-Magny G, Chaumon E, et al. Shift change handovers and subsequent interruptions: Potential impacts on quality of care. J Patient Saf 2014;10:29-44.

17. Li SYW, Magrabi F, Coiera E.A systematic review of the psychological literature on interruption and its patient safety implications. J Am Med Inform Assoc 2012;19:6-12.

18. Horwitz LI, Krumholz HM, Green ML, Huot SJ. Transfers of patient care between house staff on internal medicine wards: A national survey. Arch Intern Med 2006;166:1173-1177.

19. Cosby KS, Croskerry P. Profiles in patient safety: Authority gradients in medical error. Acad Emerg Med 2004;11:1341-1345.

20. Chang VY, Arora VM, Lev-Ari S, D'Arcy M, Keysar B. Interns overestimate the effectiveness of their hand-off communication. Pediatrics 2010;125:491496.

21. Kahneman, D. Attention and Effort Englewood Cliffs, NJ: Prentice-Hall Inc.; 1973. Available at: https://www.princeton.edu/ kahneman/docs/attention_ and_effort/Attention_lo_quality.pdf. Accessibility verified September 10, 2014.

22. Redelmeier DA, Shafir E. Medical decision making in situations that offer multiple alternatives. JAMA. 1995;273:302-305.

23. Woods DM, Holl JL, Angst D, et al. Improving clinical communication and patient safety: clinician-recommended solutions. In: New Directions and Alternative Approaches. July 2008. Agency for Healthcare Research and Quality, Rockville, MD. Available at: http://www.ahrq.gov/professionals/ quality-patient-safety/patient-safety-resources/resources/advances-inpatient-safety-2/index.html. Accessibility verified September 10, 2014.

24. Institute for Safe Medication Practices. Medication error prevention "toolbox." Medication safety alert. June 2, 1999. Available at: http://www. ismp.org/newsletters/acutecare/articles/19990602.asp. Accessibility verified September 10, 2014.

25. Gordon M, Findley R. Educational interventions to improve handover in health care: A systematic review. Med Educ 2011;45:1081-1089.

26. DeRienzo CM, Frush K, Barfield ME, et al. Handoffs in the era of duty hours reform: A focused review and strategy to address changes in the accreditation council for graduate medical education common program requirements. Acad Med 2012;87:403-410.

27. Riesenberg LA, Leitzsch J, Little BW. Systematic review of handoff mnemonics literature. Am J Med Qual 2009;24:196-204.

28. Horwitz LI, Moin T, Green ML. Development and implementation of an oral sign-out skills curriculum. J Gen Intern Med 2007;22:1470-1474.

29. Moseley BD, Smith JH, Diaz-Medina GE, et al. Standardized sign-out improves completeness and perceived accuracy of inpatient neurology handoffs. Neurology. 2012;79:1060-1064.

30. Flanagan ME, Patterson ES, Frankel RM, Doebbeling BN. Evaluation of a physician informatics tool to improve patient handoffs. J Am Med Inform Assoc 2009;16:509-515. 
31. Palma JP, Sharek PJ, Longhurst CA. Impact of electronic medical record integration of a handoff tool on sign-out in a newborn intensive care unit. J Perinatol 2011;31:311-317.

32. Petersen LA, Brennan TA, O’Neil AC, Cook EF, Lee TH. Does housestaff discontinuity of care increase the risk for preventable adverse events? Ann Intern Med 1994;121:866-872.

33. Boggan JC, Zhang T, Derienzo C, Frush K, Andolsek K. Standardizing and evaluating transitions of care in the era of duty hour reform: One institution's resident-led effort. J Grad Med Educ 2013;5:652-657.

34. Graham KL, Marcantonio ER, Huang GC, Yang J, Davis RB, Smith CC. Effect of a systems intervention on the quality and safety of patient handoffs in an internal medicine residency program. J Gen Intern Med 2013;28:986993.

35. Starmer AJ, Sectish TC, Simon DW, et al. Rates of medical errors and preventable adverse events among hospitalized children following implementation of a resident handoff bundle. JAMA 2013;310:2262-2270.

36. Horwitz LI. Does improving handoffs reduce medical error rates? JAMA 2013;310:2255-2256. 